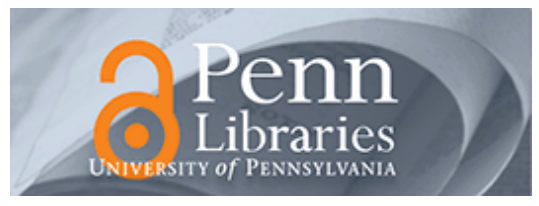

University of Pennsylvania

ScholarlyCommons

1992

\title{
Insiders and Outsiders in Baluchistan: Western and Indigenous Perspectives on Ecology and Development
}

Brian Spooner

University of Pennsylvania, spooner@sas.upenn.edu

Follow this and additional works at: https://repository.upenn.edu/anthro_papers

Part of the Agriculture Commons, Anthropology Commons, Geography Commons, Human Ecology Commons, and the Race and Ethnicity Commons

\section{Recommended Citation (OVERRIDE)}

Spooner, B. (1992). Insiders and Outsiders in Baluchistan: Western and Indigenous Perspectives on Ecology and Development. In M. Dove and C. Carpenter (Eds.), Sociology of Natural Resources in Pakistan and Adjoining Countries (pp. 430-444). Lahore, Pakistan: Vanguard Books. 


\title{
Insiders and Outsiders in Baluchistan: Western and Indigenous Perspectives on Ecology and Development
}

\author{
Abstract \\ We have generally become used to the idea that ethnographers are a part of what they study. They live in \\ the community they study and participate in the events and (ideally) in the social and cultural processes \\ which they analyze and interpret. They cannot stand either theoretically or methodologically outside what \\ they study - even though we do not perhaps all of us always manage to follow through with the \\ implications of this condition. \\ The evolutionary ecologist knows implicitly that his professional activity, like all other human activity, \\ takes place within the evolutionary process. But this orientation towards his subject matter tends to be \\ very different from that of the ethnographer. Other investigators, and particularly economists and \\ development planners, study unequivocally from without - they translate the laboratory-objectivity \\ tradition of Western scientific method into the field. The growing emphasis on popular participation in \\ development planning and implementation draws attention to these differences of orientation. In this \\ chapter a case from Baluchistan will illustrate the significance of the difference. \\ Disciplines \\ Agriculture | Anthropology | Geography | Human Ecology | Race and Ethnicity | Social and Behavioral \\ Sciences
}




\section{V.2}

\section{INSIDERS AND OUTSIDERS IN BALUCHISTAN: WESTERN AND INDIGENOUS PERSPECTIVES ON ECOLOGY AND DEVELOPMENT}

Brian Spooner

We have generally become used to the idea that ethnographers are a part of what they study. They live in the community they study and participate in the events and (ideally) in the social and cultural processes which they analyze and interpret. They cannot stand either theoretically or methodologically outside what they study - even though we do not perhaps all of us always manage to follow through with the implications of this condition.

The evolutionary ecologist knows implicitly that his professional activity, like all other human activity, takes place within the evolutionary process. But this orientation towards his subject matter tends to be very different from that of the ethnographer. Other investigators, and particularly economists and development planners, study unequivocally from without - they translate the laboratory-objectivity tradition of Westem scientific method into the field. The growing emphasis on popular participation in development planning and implementation draws attention to these differences of orientation. In this chaptcr a case from Baluchistan will illustrate the significance of the difference.

\section{ECOLOGY AND ETHNOGRAPHY}

We use the word "ecology" in two senses. It was coined to denote the scientific study (-logia) of "household" (oiko-) relations in and between communities, in and between biological populations, and between them and their physical environment. It has come to be used also for sets of those relations themselves. We often confuse these two meanings. 
Ecology as a type of study has been pursued in various paradigms, most particularly a systemic "ecosystems" paradigm, and (more commonly in recent years) an evolutionary paradigm. In either of these paradigms it has been understood mainly as a natural science, deriving historically from biology, and using natural-science assumptions and models. Where social scientists have talked ecology - calling it cultural ecology, human ecology, or anthropological ccology - in their studies of human activities in relation to their natural matrix, they have explicitly borrowed concepts from biological ecology, and have talked in terms of adaptation, niche, etc. They have been concerned with the problem of explaining how human activities and experience are caused, conditioned, or affected by natural processes and conditions, rather than the other way round. Hlaving no concepts that apply to both sides of the equation, physical-biological and human-cultural, they have tried applying concepts borrowed from the biological side. ${ }^{1}$ Whether they begin from systemic or evolutionary assumptions, they run into similar problems: on the one hand we have not yet found a way to rclate ethnographic data to evolutionary models; on the other, although for a time we had great hopes for systemic models of society, we have become disillusioned with thern.

For this reason a serious dilemma underlics the attempts of biological ecologists, development planners, and anthropologists to work together in specific projects. This dilemma vitiates most ecologically oriented work related to development. (It is worth noting that in the past it has also had the effect of separating ecological anthropologists theoretically from their colleagues.) The dilemma is rarcly faced. Whatever the focus of their work, biological ecologists tend implicilly to. include human activity and its effects in their studics. However, as biologists they cannot treat human activity on the same level as the activity of other species, because as fellow human beings they impute values and intentions to it. Perhaps partly for this reason, they tend to treat it as intrusive.

There is good reason for them to treat human activity as intrusive. The organization of human activity commonly tuanscends the boundaries of ecosystems or habitats, and cannot therefore be usefully analyzed in terms of the ecologists' universe of study. Although human societies and cultures may be products of biological evolution, social and cultural processes do not fit into ecological systcms or "communities". But ccologists' reasons for treating human activity as intrusive are more complicated than this, and not always entircly explicit: if they can manage to exclude it, there is nothing to prevent them from formulating their prob- 
lems, hypotheses, methods, and solutions with the objectivity that is de rigeur in the Western scientific tradition. If they admit the presence of human activity on a level with other (nonhuman) activities, they find themselves in the position of having to deal with members of their own species (if not their own actual "population" or "community"), with whom, unlike the members of other species in their universe, they are unavoidably related (in the sense that their objectivity is compromised) by differences of interests and values - essentially, that is, by a political and moral (rather than a scientific) relationship (cf. Tucker 1977): They avoid this problem by treating all human activity as extraneous to the ecosystem. By thus reserving scientific objectivity for themselves they deftly condemn as beyond the pale all human opinion that differs from theirs.

Natural scientists are untrained to deal scientifically with questions of politics and morals. Social scientists are prepared for questions of politics and morals, but with rare exceptions do not adequately understand ecology. Not even those rare exceptions have yet proposed how to integrate the essential positivist objectivization of ecological science (which sees science as extra-cultural and absolutc) with the semitic approaches of social science (which see scientific arguments, like all other arguments, as socially and culturally conditioned or filtered), in order to arrive at a somewhat humbler and more practical scientific ecology that would not treat human activity as intrusive. Ignoring the problem has led many (including many social scientists) to the general conviction that we know what all human beings should think and do in relation to the productivity of the renewable natural resources to which they have access, irrespective of the legitimate interests of other people in those resources.

To return to the initial distinction between objective ecology and ecological analysis: unlike ecological reality, ecological analysis is (like ethnographic description) not absolute but relative; it is relative to the social and cultural experience of the scientist. Although the ecologists' situation is far less obvious, they are in fact as much a part of what they are studying as are ethnographers of what they are studying. The identity of Western (as well as non-Western but Western-trained) ecologists derives from their place in their own society, and their society's position in the world, as well as from ideas from the cultural repertoire of their society which presently include (for example) positive thoughts about stewards of nature ("we are responsible to God and to future generations for the condition of the natural world") and negative thoughts about the destructiveness of the "frontier mentality" ("there will always be more out there for us to exploit to our advantage"). 
It is not too difficult to grasp and to explain the possibility of cultural variation in ecological orientation. We have become accustomed to the idea that different people from different cultural backgrounds have differ. ent values and consequently are likely to have different perceptions of nature and of their relation to it. But the ability to appreciate social differences seems to lie deeper in our cultural consciousness. Though we recognize them instinctively, we repress them, or at best proceed on the assumption that they are artificial and easily overcome, whereas in fact the more we seek to overcome them, the more they control our daily lives. Our feelings towards nature and the natural environment turn out to be a reflection of the way we relate to other pcople. Our ccological values are to a large extent a function of our social values.

This social dimension of ecology obscures our view of development problems. It is therefore on social variation in relation to territory and natural resources that $I$ shall focus in the remainder of this chapter.

\section{ECOLOGY AND SOCIAL CONTEXT}

Social variables have to do with interests. Interests relate to individuals and to groups. In some cases (especially in the West) individual interests tend to take priority over group interests. In other cases (especially in some tribal societies - pace Hardin) group intercsts may take precedence over individual interests. Every ecological issue involves a range of different interests, representing conflict between individuals within a group, and between groups, between insiders, and between insiders and outsiders.

The classic case of an ecological issue between insiders and outsiders is the issue between "us" and "them", between the ecologist-consultant and the indigenous community. Mary Douglas, who has done more than anyone to sensitize us to the social mainspring of human experience, puts it this way:

Unlike tribal society, we have the chance of self-awareness. Because we can set our own vicw in a general phenomenological perspective, just because we can compare our beliefs with theirs, we have an extra dimension of responsibility. Self knowledge is a great burden (1975:230-231).

If we are to acknowledge the burden that Douglas identifies, we must take account of the fact that statements about ecology are not just right or wrong. Apart from being objcctively right or wrong, they have 
different meanings, more or less significant, according to whether one is a member of the ecological community in question or not, and (if one is a member) according to the particular position in that community that one occupies. Both the habitat and the ecological future look very different according to whether one is a hunter in a small closely knit society; or a dry-farmer, a pastoralist, or an irrigator in a society that may also include people with different resource interests; or a stecl worker in a modern complex society, where one is not committed to a particular occupation or a particular relationship to the natural environment, but may (perhaps unconsciously) feel locked into a particular cconomic class. Just as there is more than one recognized valid interpretation of a modern industrial economy (the differences correlate with different political ideas about the ideal economy), so the ecosystem may look very different according to the niche one occupies within - or outside it.

For comparison let us imagine oursclves in Disneyland. Take the case of a gazelle in an open steppe ecosystem. Although everything is indeed connected to everything else (cf. Commoner 1971:29), the survival interests of grasses and forbs, shrubs; herbivores, and predators are obviously in conflict. The ecologist stands outside the system but bases his research design implicitly on certain interrelated assumptions about productivity and diversity. However objective his research design, the ecologist is led by his assumptions to discriminate against the interests of individual creatures in favor of the survival of what he perceives as "the system". The survival of the system may, of course, be in the long-term best interests of the totality. It is definitcly not, however, in the best interests of all the component species, lct alone of all the living individuals, some of whom will inevitably sooner or later fall prey to predators. A reduction in the number of predators would, therefore, be in the best interests of some at least of the living herbivores. Similarly, a reduction in the number of herbivores would be in the best interests of many living plants.

If a gazelle could produce a study of the same ecosystem, we might expect the results to differ from those of the ccologist, inasmuch as they would, as a matter of course, be based on different values, which would derive from a different social situation. The gazelle's assumptions would of course not be disinterested. A member of the system, such as the gazelle, whose personal interests are at stake, would argue for his own survival first. But what about the ecologist? The ecologist can argue in terms of the survival of species and of the system, because survival on that level suits his own social values best. Both arguments may be equally objective and scientific, but differ on grounds of morals and per- 
sonal interest, which are socially relative. The conflict between them is always in the end resolved politically, as a function of the difference in power of the individuals or the communities or the populations in question (cf. Spooner 1982a:7). Social scientists will also recognize here the familiar problem of the actual individual versus the abstract society. However, the issue of the conflict of interest between the cheetah, the gazelle, and the shrub is introduced in order to clarify the difference of interests between the Western-trained ecologist and the nomad, the horticuituralist, or the irrigator, each in rclation to (not an ecosystem, but) all the other human, biological, and physical factors that impinge on their lives. A particular case from the Third World will show the significance of this argument for problems of development (standard of living) and ecology (habitat and natural resources).

\section{A CASE STUDY FROM BALUCHISTAN}

Baluchistan is the western province of Pakistan. The name comes from the Baluch, who comprise the majority of the population throughout most of the province, as wel' as in the neighboring province of Iran and the adjoining part of southern Afghanistan. The total population is estimated tentatively at four million. In all three countries the territory is arid and poor, and has remained for many centuries in comparative isolation from the major economic and political centers of the region. Baluch identity is symbolized in their language and oral literature and code of honour. Otherwise they are a heterogeneous collection of tribes of various origins, and the land they inhabit varies from high plateau with cold winters to subtropical coastal lowlands. They live by a mixture of dry and irrigated agriculture and pastoralism. Community organization varies between extremes of highly stratified villages (often in the past dominated by strong forts) and small egalitarian nomadic groups.

In Makran, the southwestern division of the province of Baluchistan in Western Pakistan, and across the border in Iran, the nomadic pastoralists play a particularly significant social rolc. Their continued activity provides a communications network among the settled village communities and symbolizes for those communities the values that support traditional Baluch identity. They contributc significantly, that is, to both the logistics and the morale that are essential to the continued viability of Baluch society in the area. Unfortunately, these variables do not show up in either economic or ecological analysis. 
Nomads are important for the local economy, both for what they produce and as a source of seasonal labor. They bring milk products to the local market, and they supply the necessary labor for the date harvest in the villages - the most important event in the traditional agricultural cycle, which coincides in late summer with the slack season in the pastoral cycle. They are also agricultural producers themselves. Much of the subsistence-crop production of the area depends on unpredictable river flow and runoff, which only the nomads know how to use. Small pockets of soil scattered throughout the area produce crops when a downpour happens to bring water by - if a nomad is there to channel and apply it. Although no one in the towns wants to live that life anymore, the idea of it remains an important cultural value: nomadic life is still thought of as the genuine Baluch life, which embodies the authentic Baluch virtues of honesty, loyalty, failh, hospitality, asylum for refugees, and so on.

There are no reliable figures to indicate how many of the Makran population of some 230,000 are now nomadic, nor how many of those who are nomads by socialization still spend most of the year in tents or other temporary dwellings with their families and flocks rather than taking one of the modern options of wage labor in the (until recently) booming Gulf Emirates, or wage labor in towns outside the province. We may estimate, conservatively, over 50,000.

The significance of the nomads for the future development of Makran far outweighs their numbers or their economic contribution. They are the only people who use or are ever likely to use some 90 percent of the territory of Makran. Without them the greater part of the population would be marooned in isolated oases, which on their own do not have the resources to be economically independent, and with increasing dependence on outside subsidies would gradually lose population to more attractive opportunities outside the province. With the nomads, the Baluch population as a whole forms an interdependent social and cultural, as well as economic and political, network covering the whole of the area. As long as the nomads are there, the whole of the area continues to be inhabited by people who consider it to be their territory. If the nomads leave, the settled population will see itself simply as an economically disadvantaged appendage of the national economy. As long as they remain, the total population shares a conception of ethnic provincial autonomy.

The nomads depend on the primary productivity of the semi-desert and desert areas which cover the greater part of the territory. Traditionally they make no improvement in either the pasture or the watering resources. Based on comparison with other areas of similar climate and 
soils, ecologists evaluate most of this rangeland as severely degraded. Their evaluation is made without reference to the fact that the Baluch continue to make a living out of it, and without the possibility of direct comparison with earlier data. It is an outsider's evaluation, which focuses on the vegetation rather than on the cvolving process of interaction between the vegetation and the pastoralists.

Pastoral activity is an essential component of the Baluch economy, and it contributes significantly to the social interaction and the culture of the province. Range science condemns Baluch pastoral practice. But no one has yet shown how the principles of range science might be integrated with the social conditions of this type of situation. The national economy is intruding more and more into the life of the area, helped by programs financed by USAID. A major consequence of these programs is increasing dependence of the population on the national and regional economies. For the time being, however, the pastoralist sees his main interests in continued exploitation of the range, of localized runoff, and of the socio-economic resources of the scattered settlements of the area. The farmers in the settlements depend both on the pastoralists and on the outside economy. Loss of the pastoralists would significantly reduce the viability of most of the settlements. The pastoralists can use help, but what they need is not enforced improvement of their range through enforcement of Western range science principles, but defense against the effects of the national economy. The best defense would probably be in the form of management by government of the terms of trade, manipulating prices in such a way as to reinforce local valucs, instead of subverting them.

Western range ecology, as its name implies, starts with the range. The range scientist is the self-designated steward of the plant communities of the Baluch's range. According to the principles of this science, no more herbivores should be allowed onto the range than can graze without degrading its plant communities. The pastoralist, on the other hand, sees range, domesticated animals, and people in interdependent interaction. It would probably not be too much of an oversimplification to characterize this view as one that would emphasize the convenience of the family group in the context of its social matrix. The nomad's first priority is to avoid disruption of his social relations. If this would mean reduction of the productivity of the range for future generations, that is of secondary importance. In these times of rapid change, who knows what future generations will need?

However, there is evidence to suggest that the range has remained in its current "degraded" state for a long time, over a cenury (HughesBuller and Minchin 1906-1907), and we do not have convincing evi- 
dence that current trends are adverse. Unfortunately, no one will finance the studies that would be necessary to establish what the trends are. Such studies - which would construct an insider's ecology - would need to focus on interactions of pastoral technology, animal behavior, and plant communities over a period of time (cf. Nyerges 1982).

\section{COMPARABLE CASES}

Such cases of insider's ecology are beginning to appear. In Africa pastoralists have the reputation of seeking to maximize numbers of animals. Recent work by Sandford (1982 and in press) has provided a rational basis for this emphasis in range-science terms by synthesizing accumulated existing information on what might be called indigenous range-management practices. Cossins (in press), using data gathered by ILCA (International Livestock Centre for Africa) research teams, has demonstrated that many pastoral systems in sub-Saharan Africa are also in fact more efficient in terms of productivity per hectare than ranching systems in either developing or developed countries. But as Legesse (in press) has shown in his study in northern Kenya, in order to understand what is going on ecologically among the Boran and the Gabra pastoralists, it is necessary to study the inter-dependence of their two sets of activities. What we need more than anything else, however, is some reconstruction of what has actually happened in the relationship between pastoralists and their resources over a significant period of time. Cassanelli is probably the first historian to work in the historical ecology of pastoralists. He brings the skills of an historian to bear on the problem, without the biases of either the ecologist or the anthropologist (in press).

In each of these cases there are obviously several different ways of defining the universe of reference - cach producing different results. The Western ecologist wants primary productivity at the expense (if necessary) of current livelihood - on the assumption that we are otherwise sacrificing the livelihood of future gencrations to the interest of the living, and that we should not do that. The Baluch pastoralist sees market centers and agriculture as a resource on a level with the range. He wants more in return for his product, but his first priority is the security of his social life. Else he will think of leaving his niche. The range ecologist considers that the local range, and therefore also the global resource base, would be better off if the pastoralist would leave his niche. The Baluch farmer sees the nomads as a resource. He wants to kecp them where they are; otherwise only economic subsidies will keep him where he is. 
It would be easy to add examples of other forms of land use. A similar case could be made in the much more complex situation of the Punjabi irrigator (Spooner 1984b:28-39). But perhaps more interesting here is the case of the Susu in northwestern Sierra Leone (Nyerges 1985). Susu swiddeners do not have enough labor to produce an adequate food supply, though shortage of labor leads them to clear plots inadequately, with the result that the degradation of the forest procecds at a slower pace than might otherwise be the case; recurrent famine kecps population and the labor force down; they cannot intensify to produce more food, because of insufficient labor; they cannot reduce labor inputs and de-intensify to fit labor availability, because they dare not risk lower production of food. But we cannot help them, because if we introduce labor or technology from outside, what we introduce will have a higher value for them than the local resources and they will degrade faster and have less interest in conserving local resources.

Since people do not fit casily into ccosystemic frames of reference, the shift from a systemic to an evolutionary paradigm in ecology has helped us to develop ways of incorporating local interests and points of view into ecological analysis. However, in case I may have appeared to argue that social relativism is more important than global survival, let me in concluding emphasize that this is not my vicw. As I stated at the beginning, ccology is real; but ccological analysis derives from a particular social and cultural (and perhaps even ideological) position. To return to the Bambi-like example: without human intervention the gazclle population would probably never expand to the point where it disrupts the eco"system". Malthusian factors would take care of them first. But human populations, having culture, are not always restricted by Malthusian pressures. On the contrary, they are often able to act out the scenarios of Marx and Boscrup, and have done so periodically from the Neolithic up to the Green Revolution.

Furthermore, human beings, having culture, have rights - not only human rights but civil rights. We scientists and consultants learn our morality in two different arenas. When we mix them we do so as amatcurs. If we stand outside the ccosystem (as we do in the case of the gazclle and the Baluch) we artificially kecp morality out of the discussion. In fact, however, every ccological question that involves human activity is not only an ccological question, but also both a moral question and a political question. Development has tended to ignore the political and moral dimensions of ccological (among other) problems, and has concentrated on the scientific and technological solution of the problem qua objectificd ecological problem only. In the long term it cannot be 
done. The ecological dimension of the problem will be resolved only as part of a comprehensive resolution of the whole problem, including its moral and political dimensions. The primary productivity of the rangelands of Baluchistan must be taken care of not by ecologists but by politicians, using ecological among other information, at the level of national planning, adjusting the terms of trade so as to rcinforce local values insofar as they are politically and morally desirable, making economic planning an instrument of social planning rather than a victim of ecological planning. 


\section{NOTES}

1. It is not pertinent here that some of these concepts, such as "community", were originally derived from social studics. This borrowing has becn written up by Rapport and Turner (1977) and Richerson (1977).

2. Passmore (1974a) reviews the history of thesc various attitudes towards nature in our own history in a book that helps in many ways to "remove the rubbish" (Passmore 1974b) from our everyday thinking about ccology.

3. This essay builds on three carlier cssays in which I argue that (a) ecology is relative (1982b), (b) assessments of the ccology of dry lands should be assessments of the evolving relationship between human culturally organized activities and natural processes (1982a), and (c) the relationship betwecn a population and its territory may be as valuable and as fragile as the ccosystem, and perhaps should be given planning priority over the ecosystem (1984a). My aim here has been to show how, without giving in to cultural relativism with regard to ccological analysis, there may be a valid ccologically relevant local point of view that would direct our attention to more fruitful development objectives. 


\section{REFERENCES CITED}

Cassanelli, Lee

In press. Historical Perspectives on Pastoral Devclopment: Examples from the Somali and the Maasai, Eastern Africa. In The Developing World: Challenges and Opportunities. Proceedings of the Sccond International Rangeland Congress, Adelaide, 1984. Brian Spooncr, ed.

Commoner, Barry

1971 The Closing Circle. Now York, NY: Knopr.

Cossins, N.J.

In press. The Productivity and Potential of Pastoral Systems. In The Developing. World: Challenges and Opportunities. Procecdings of the Second International Rarigelands Congress, Adelaide, 1984. Brian Spooner, ed. (Sec also ILCA Bullctin No.21, Pp. 10-15.)

Douglas, Mary

1975 Implicit Meanings. London: Roulledge and Kegan Paul.

Hughes-Buller, R., and C.F. Minchin

1906-1907. Makran and Kharan. Volumes 7 and 7A of Baluchistan District Gazetteer. Bombay: Time Press.

Legesse, Asmarom

In press. Gabra and Boran Pastoral Ecology. In The Developing World: Challenges and Opportunities. Procecdings of the Sccond International Rangelands Congress, Adelaide, 1984. Brian Spooner, ed.

Nyerges, A. Endre

1982 Pastoralists, Flocks and Vegetation: Processes of Co-adaptation. In Desertification and Development: Dryland Ecology in Social Perspective. Brian Spooner and H.S. Mann, eds. Pp. 217-248. London: Academic Press.

1985 Swidden Agriculture and Savannization of Forests in Sierra Leone. Paper presented at 84th Annual Mecting of the American Anthropological Association. 
Passmore, John

1974a Man's Responsibility for Nature. New York, NY: Scribners.

1974b Removing the Rubbish. Encounter 42(4):11-24.

Rapport, D.J., and J.E. Turner

1977 Economic Modcls in Ecology. Science 196:367-373.

Richerson, Peter J.

1977 Ecology and Human Ecology: A Comparison of Theorics in the Biological and Social Sciences. American Enthnologist 4:1-26.

Sandford, Stephen

1982 Pastoral Strategies and Descrtification: Opportunism and Conservatism in Dry Lands. In Desertification and Development: Dryland Ecology in Social Perspective. Brian Spooner and H.S. Mann, eds. Pp.61-80. London: Acadcmic Press.

In press. Traditional African Range Management Systems. In The Developing World: Challenges and Opportunities. Proceedings of the Second International Rangelands Congress, Adelaide, 1984. Brian Spooner, cd.

Spooner, Brian

1982a Rethinking Desertification: The Social Dimension. In Desertification and Development: Dryland Ecology in Social Perspective. Brian Spooncr and H.S. Mann, cds. Pp. 1-24, London: Academic Press.

1982b Ecology in Perspectivc: The Human Context of Ecological Rescarch. International Social Science Journal 34:396-410.

1984a Nomads in a Wider Socicty. Cultural Survival Quarterly $8(1): 23-25$.

1984b Ecology in Development: A Rationale for Three-Dimensional Policy. Tokyo: United Nations University. 
Spooncr, Brian, ed.

In press The Developing World: Challenges and Opportunities. Procecdings of the Second International Rangelands Congress, Adelaide, 1984.

Spooner, Brian, and H.S. Mann, eds.

1982 : Desertification and Development: Dryland Ecology in Social Perspective. London: Academic Press.

Tucker, William

1977 Environmentalism and the Lcisurc Class: Protecting Birds, Fishes, and Above All Social Privilege. Harpers 255(1531):49-67. 